\title{
CARBON LEAKAGE ALONG WITH THE GREEN PARADOX AGAINST CARBON ABATEMENT? \\ A REVIEW BASED ON CARBON TAX
}

\author{
Sahin Akkaya, Prof. Dr. ${ }^{1}$ \\ Ufuk Bakkal, Prof. Dr. ${ }^{2}$ \\ Istanbul University \\ Faculty of Economics \\ Department of Public Finance \\ Beyazit/Fatih, 34452 Istanbul \\ ${ }^{1}$ e-mail: akkays@istanbul.edu.tr \\ ORCID: 0000-0003-2394-7232 \\ 2 e-mail:ubakkal@istanbul.edu.tr \\ ORCID: 0000-0001-5903-0544
}

Received 27 June 2019, Accepted 6 April 2020

\begin{abstract}
Research background: Insufficient global cooperation in carbon pricing against global warming has the risk of global carbon emissions rise because of carbon leakage. The effect of a carbon tax on the present supply of fossil fuels is also valuable in regard to global carbon emissions.

Purpose: The purpose of this study is to gain more insights into the effects of carbon leakage along with the green paradox on global carbon emissions by reviewing the relevant literature.

Research methodology: We provide the problem linked to carbon leakage and the green paradox in the introduction. Then, the effects of carbon leakage and the green paradox on global carbon emissions are elaborated separately. Finally the mutual effects of carbon leakage and the green paradox are reviewed comprehensively.

Results: It is seen that various factors like interest rates, fossil fuel extraction costs, the fossil fuel reserves to be discovered in the future and carbon tax incidence are equally important determinants in regard to global carbon emissions.
\end{abstract}

Novelty: This study provides an insight into the mutual effects of carbon leakage and the green paradox on global carbon emissions by reviewing the primary literature in the field.

Keywords: Global warming, carbon tax, carbon leakage, green paradox

JEL classification: Q54, Q56, Q58, Q59 


\section{Introduction}

All antropogenic greenhouse gases including carbon dioxide cumulating in the atmosphere is the main reason of global warming (see Cline, 1991). The insufficient global cooperation for carbon abatement is causing the risk of global carbon emission rise because of carbon leakage. This carbon leakage, arising from shifting productions to countries that are not using carbon reducing policy instruments due to cost increasing effects is known as direct carbon leakage. Apart from that, shifting productions to countries that the producers deem more advantageous for them due to lower factor costs, energy, raw material, low-cost labor etc. constitutes another important reason for carbon leakage. This kind of carbon leakage is called indirect carbon leakage (Eckersley, 2010, p. 371). Either indirect or direct, it is required to consider the negative effect of the resultant carbon leakage on global carbon emissions. Moreover, the measures, which may be taken against direct and indirect carbon leakage arising from the concern about international competition will also have an effect on global carbon emissions.

On the other hand, it is required to not overlook the effect of a policy for reducing demand for fossil fuels on the supply of fossil fuels. Because the lack of consideration of the effect of a carbon abating policy instrument such as carbon tax on the present supply of fossil fuels will cause the non-observance of the real effect of the relevant policy instrument on carbon emissions. The risk of a rise in carbon emissions depending on the increasing consumption of fossil fuels due to increased present fossil fuel supply by the expectation that the policy instruments used will decrease the demand for fossil fuels tomorrow has been added as the term of the green paradox to the relevant literature (see Sinn, 2008).

It may be thought that direct carbon leakage caused by unilateral carbon abatement policies and the green paradox have opposite effects of each other on global carbon emissions. Of course, it is argued that indirect carbon leakage affects carbon abating policies, but in this study our purpose is to analyze how direct carbon leakage ${ }^{1}$ along with the green paradox affect global carbon emissions mainly by reviewing the relevant literature. In the first chapter, the effects of carbon leakage and the green paradox on global carbon emissions are scrutinized separately. Reviewing the effects of carbon leakage along with the green paradox on global carbon emissions is addressed in the second chapter. Finally, the conclusions obtained and the evaluations made are available.

\footnotetext{
1 From now on it is called carbon leakage.
} 


\section{Carbon tax, carbon leakage, and the green paradox}

Carbon leakage which is being qualified as a spatial version of the weak green paradox by F. van der Ploeg and C. Withagen (2015), is an important concept in terms of being able to determine whether it creates a mitigating effect on global carbon emissions and thus global warming along with the green paradox. And the term of the green paradox which was added to the literature by Hans-Werner Sinn (2008) has started to be used in order to express the present increase of carbon emissions through the effect of climate policy instruments, such as carbon tax, on the supply of fossil fuels.

Carbon tax, ${ }^{2}$ intending to internalize the global external cost arising from carbon dioxide emissions, is for the effective use of the atmosphere in terms of carbon emissions by equalizing the marginal social cost of decreasing carbon emissions, and the marginal social benefit coming from the mitigation of global warming (Herber, Raga, 1995, p. 529). As summation technology is valid in terms of the provision of global public goods such as the global warming mitigation policy, the benefit of any greenhouse gas reduction policy depends on the summation of greenhouse gas reduction amounts from each country. The country that carbon dioxide emission arises from is not important in relevance to the global cost distribution of climate change. Because of the fact that one country is a substitute for another one in terms of greenhouse gas reduction, some countries do not want to contribute to the provision of public goods called the global warming mitigation policy, and thus causing insufficient emission reduction (Sandler, 2003, pp. 134-136). Even if insufficient, as all countries in the world benefit from measures for carbon dioxide emission reduction, such as carbon tax, including the ones which do not contribute. For that reason, these countries are benefiting from these global public goods as a free rider. Even if the countries do not have foreign trade with each other, this free rider behavior will be able to be observed. But the negative effect of a carbon reducing policy on international competition is making the problem of free riding more important (Barrett, 1999, p. 215). Naturally, the insufficient reduction of carbon emissions does not just arise from the free riding behavior of countries. In this respect, the different distribution of benefits arising from carbon reduction among countries, and the different carbon reduction cost of countries are equally important issues.

\footnotetext{
2 Lack of anticipating future economic and technological developments in the carbon reduction policy to be applied on a global scale made it impossible to calculate the real marginal cost of carbon reduction. In such a case, even if the tax is determined as per the estimated marginal cost of reduction of one ton of carbon, carbon tax being applied both on a global and national scale will not generate cost efficiency (see Dinan, 2009, pp. 536-537).
} 
If it is assumed that the marginal cost of the carbon reduction each country faces is the same, full cooperation in the global warming mitigation policy will conclude to a decrease of carbon emissions at an amount equalizing the marginal cost of such carbon reduction to the marginal benefit function consisting of the summation of the marginal benefit functions of each country obtained from gas reduction. But the reduction of carbon emissions by any country until equalizing the marginal cost of gas reduction to its own marginal benefit is beneficial for the country. In this case, lower emission reduction will be provided compared to a full cooperation situation. Besides the marginal benefit and cost functions of countries relevant to greenhouse gas $\left(\mathrm{CO}_{2}\right)$ reduction, the number of these countries and whether they are symmetrical or not are important. In case countries are asymmetrical, the difference of carbon emission reduction between non-cooperative and full cooperative behavior decreases compared to the situation in which countries are symmetrical. (Barrett, 1999, pp. 197-200)

\subsection{Carbon tax and the green paradox}

According to the green paradox argument of Hans-Werner Sinn (2008), as the owners of fossil fuel sources intend to maximize the value of the wealth they own, the instruments intending to decrease fossil fuel demand by increasing prices will not be able to flatten out the carbon supply curve. When the measures taken decrease the discounted value of carbon's future price below its present price, increasing the present supply of fossil fuels will become more profitable in respect of fossil fuel producers. In this case, as the present price of fossil fuel decreases, the present carbon emissions might be able to increase. There are many neoclassical models including the study performed by Hotelling in 1931 regarding what the optimal output and investment should be in petroleum and mines (see Smith, 2012), and nowadays we can observe that the model of Hotelling is being used mainly in the studies performed regarding to the supply of fossil fuels.

Within the frame of Hotelling's model, the possibility that measures taken for increasing the present price of fossil fuels may create an effect of increasing the present supply of fossil fuels points to one of the important perils of today's carbon reduction policy. In this respect, the success of policy measures against global warming depends on whether or not flattening the carbon supply curve in the world energy markets is realized. When $S, g$ and $R$ indicated respectively, the fossil fuel reserves of the producer, the cost of extraction of one unit of carbon (fossil fuel) and the extraction amount of fossil fuel, $g(S) R$ shows the total extraction cost of fossil fuel. When $P$ is the world price of fossil fuel, the producers of fossil fuels try to maximize the present value of their cash flow $(P-g(S)) R$. When "i" indicates the interest rate that the owners 
of fossil fuel will obtain in the case of investing their cash flow, fossil fuel producers investing in the capitals market will earn $i[P(t)-g(S(t))]$ in addition to $P(t)-g(S(t))$ gained by the selling of one unit of fossil fuel (extracted in $t$ period). If the producers do not extract fossil fuels today and keep it in the ground, they will obtain the $P^{\prime}$ price due to the potential increase in the price of fossil fuel in addition to $P(t)-g(S(t))$. When $i=P^{\prime} / P-g(S)$, fossil fuel producers will be indifferent to extracting the fossil fuel either today or tomorrow. If the carbon tax rate is increased faster than the increase of the share of extraction cost of fossil fuel within the total cost, keeping the fossil fuel in the ground will be more profitable than selling it and investing the income in the capitals market. On the contrary, if the carbon tax rate to be applied in the following period is increased with a rate higher than the interest rate, the fossil fuel producers will prefer to increase the present extraction (Sinn, 2008).

And R. Gerlagh (2011, p. 82) by considering the concept of the green paradox in a different manner, had enabled the inclusion of the global warming literature his weak and strong green paradox classification. According to this new classification, the green paradox addressed by Hans-Werner Sinn is actually a weak green paradox. In the strong green paradox, R. Gerlagh is taking the effect of measures against global warming on aggregate welfare as a reference. Thus, it is required to have a long term perspective in order to be able to determine whether the strong green paradox arises or not. According to R. Gerlagh, a weak green paradox being deemed as the present effect should not be the main concern. Because current emissions may be increased, but if the emissions in the future decrease sufficiently, climate change in the long term may be less severe. But, if cheaper clean energy increases the net present value of the costs of global warming associated with emissions, a strong green paradox occurs. M. Hoel (2011, pp. 847848) evaluates that R. Gerlagh uses the concept of a strong green paradox in order to define the fact that the policies intending to mitigate climate change are increasing the total climate cost. According to M. Hoel, as the total climate costs depend not just on present emissions but also on all future emissions, the distinction of a weak and strong paradox is important. For this reason, it is essential to take into account climate policies with increasing emissions in the near future but decreasing emissions in the future at a very high level resulting in a decrease in the cost of total climate change.

\subsection{Carbon tax and carbon leakage}

Marginal cost differences caused by development differences among countries are another reason for the insufficient supply of global public goods called as such as the global warming mitigation policy. The high marginal costs of countries in slowing down climate change are 
indicators that they have insufficient capacity. And the insufficient capacities of low-income countries due to the inability to allocate enough sources against global warming may cause large countries such as the USA to not contribute to the measures against global warming by considering or alleging that they will face more costs than benefits (Arce, 2004, pp. 554-555).

The measures taken unilaterally by developed countries for reducing carbon emissions are causing carbon leakage arising from both importation and exportation (Droege, 2011, p. 1192). In terms of importation, carbon leakage arises from selling products which do not have any carbon cost to countries taking measures for carbon emission reduction. The products imported from countries not having carbon costs due to the lack of taking measures for the reduction of carbon emissions can be priced lower than compared to the products produced within the importing country. In terms of exportation, carbon leakage comes from having more exportation capability to the third countries of the countries having no carbon costs compared to the carbon reducing ones. In other words, due to measures such as carbon tax, the carbon reducing countries will lose their previous export markets to the countries not taking measures for carbon emissions reduction.

On the other hand, the developments in green technologies (innovation feedbacks) due to carbon reduction policies and the rebound effect have the power to change the supply of fossil fuels through the expected effect of policy instruments for decreasing the demand for fossil fuels on the present and future prices of fossil fuels. Primarily, the generation of green technologies accelerated by the use of carbon reduction instruments can create an effect of decreasing carbon emissions by stimulating new technological developments. But it can eliminate a part of the positive effects via reducing fossil fuel prices due to the generation of green technologies, and thus increasing the demand for fossil fuels. Secondly, because energy saving arising from the use of carbon reducing instruments has a reducing effect on energy prices, it is possible to cause a rise in global carbon emissions due to not only income effect increasing the demand for nonenergy products but also the substitution effect increasing the energy demand depending on the price elasticity in the countries with or without carbon cost. In this case, the effect of global carbon reducing measures becoming possible by ensuring global cooperation with the development and the rebound effect of green technologies is decreasing the possibility of increasing present fossil fuel supply by preventing a high level of decrease in the future prices of these products (Fölster, Nyström, 2010, pp. 224-228).

When production moves to countries not taking carbon reducing measures from countries taking measures, another significant question is whether or not foreign trade will cause the green paradox due to carbon leakage. In this respect, the effect of the gradual liberalization of foreign 
trade on global carbon emissions is important in the case where only specific countries have the liability of carbon reduction as in the Kyoto Protocol. O. Kuik and R. Gerlagh (2003) had concluded that the effects of the liberalization of the foreign trade of energy products and nonenergy products through decreasing import taxes are different from each other. In the study, the effect on global emissions in the situation of more liberal foreign trade, as the result of the Uruguay Round decisions by considering the pollution havens and the factor endowment hypotheses was examined empirically and found that the results supported both hypotheses. According to the study, more liberal foreign trade is stimulating the development of more carbon intense industries in OECD countries even under binding carbon dioxide targets. In other words, more liberal trade is compensating partly the loss of competitiveness of energy intense industries in OECD countries having carbon reduction liability due to the Kyoto Protocol. This finding supports the factor endowment hypothesis. It had been concluded that in most of the countries out of the "Annex I list" to the Kyoto Protocol, in other words in most of the countries not being under liability, more liberal foreign trade is changing the economic structures in favor of the sectors in which emissions are not intense. This is in conformity with the factor endowment hypothesis. On the other hand, the findings indicate that the economies of China and the Middle East are structuring again towards more energy intense industries. And it is asserted that it may be better explained with the pollution haven hypothesis. As a general result, it can be emphasized that despite the occurrence of modest carbon leakage due to more liberal trade, the main reason for increasing carbon leakage is the technology which is used. According to this, the change in the economic structure is less important than the change in factor usage, more liberal trade makes carbon leakage increase. Moreover, the conclusion of O. Kuik and R. Gerlagh (2003) regarding to that even if the effect of the liberalization of trade on global emissions is negative, the increase of world welfare with more liberal trade is remarkable. Certainly this result largely depends on which products' foreign trade are liberalized. In here, ensuring more liberal foreign trade in non-energy products is causing this result. It seems impossible that the liberalization of the foreign trade of energy products would ensure the increase of global welfare by compensating the cost caused by carbon leakage.

Due to the fact that the carbon reducing policy tools used by some countries are not sufficiently decreasing the demand for fossil fuels, in other words due to the fact that carbon leakage is at a significant level, the future price reducing effect of these fuels will remain limited. For this reason, the possibility of directing the fossil fuel producers to increase their present production will decrease. And this will lower the possibility of the occurrence of a weak green paradox, and therefore the possibility of present carbon emissions increase. On the other hand, 
it is essential to consider the possibility that the fossil fuel producers will increase present fossil fuel production with the concern that fossil fuel prices will decrease more in the future will increase in case carbon leakage does not occur. But there are various factors determining the present and future supply of fuels containing carbon. These factors will determine whether or not a weak and strong green paradox will occur along with carbon leakage.

In the real world, different carbon emission prices occur due to different policy instruments. At the same time, the challenges faced by countries like Sweden, France and Canada having different social and political conditions for the acceptance and implementation of the carbon tax may be valuable for drawing some lessons for the future of carbon taxation. (Criqui, Jaccard, Sterner, 2019) On the other hand, even if the countries taking measure against global warming use the same policy instruments such as carbon tax, because of different tax rates, different carbon prices may occur. For instance, there is a complex system consisting of carbon tax, quota system and other complementary climate policies in EU member states. For this reason, M. Hoel (2011), based on the idea that assuming countries taking measures are homogeneous is not realistic, had established a simple two-country economy model by deeming that countries are heterogeneous, and had addressed the effects of the implementation of different climate policies, different carbon taxes or subventions by countries. In homogeneous countries, carbon tax is the same. The increase of that tax rate is causing fossil fuel extraction to be carried forward from today, and thus a reduction of climate costs. On the other hand, when countries become heterogeneous in terms of carbon tax or subventions they apply; it is not possible to easily comprehend the effects of increasing taxes. If carbon tax is increased in countries which were previously applying low tax, the extraction of fossil fuel will be able to be accelerated, and this would imply increasing climate costs. In such a case, a strong green paradox will occur. But, we can argue that assuming that those countries taking measure and not taking measure are asymmetrical instead of assuming that they are symmetrical will strengthen the loadstar characteristic of the results of models developed for the effects of carbon leakage and the green paradox on global emissions for policy makers.

In some models, formed for revealing the mutual effect of carbon leakage and the green paradox on global carbon emissions, the assumption that fossil fuel production may be increased in the short term constitutes another point drawing attention. But due to factors limiting production, it will not be possible to increase fossil fuel production in the short term. In fact, in order to be able to increase production at known fossil fuel reserves, exploration and extraction planning is required regarding to how much and when investment will be made. For instance, as the production of each producer in the oil sector is subject to technological and geological 
limitations, oil extraction at a specific reserve cannot be easily increased in the short term. If the equilibrium price of oil falls to the medium term from the short term due to the tax, making investments for exploration and expansion of current reserves in order to be able to increase the present supply will increase the supply not in the short term but in the following period (Cairns, 2014). Moreover, as a global carbon tax affects fossil fuel producing countries' profits throughout the competition and timing effects, it is needed to include oil and coal producing countries separately in the analysis of global carbon emissions (see Coulomb, Henriet, 2018).

\section{Does carbon leakage along with the green paradox mean more carbon emissions?}

As aforementioned, the issue of what the effect carbon leakage with the green paradox which may be labeled as the inter-temporal version of carbon leakage will be on global carbon emissions is very important in terms of being able to determine whether the measures taken create an effect of slowing down global warming or not.

\subsection{The green paradox and carbon leakage: important factors dealt with for global carbon emissions}

The interest rate as discount rate which is important in terms of the green paradox is also important in terms of the effect of carbon leakage with the green paradox on global carbon emissions. For this reason, the issues of how the interest rate will be determined in the established models, and whether the interest rate is deemed as constant among periods or not will determine the loadstar characteristic of the results obtained. Deeming that the interest rate as a significant price determining the decision of extraction of fossil fuels among periods as well as saving and investment decisions is constant among periods is not a realistic assumption. For instance, in case the effect of the green paradox increases present oil consumption, it will cause excessive product supply by the current interest rates. In this case, if investments are not present in the general equilibrium model established, it will be required to have a decreasing interest rate for the elimination of excessive product supply. Depending on this decrease in the interest rate, the desire of fossil fuel producers to extract fossil fuels in the current period will decrease. On the other hand, when it is considered that capital is also being used in investments made for realizing oil production in the case of the inclusion of investments in the general equilibrium model established, it will be observed that a decrease in fossil fuel extraction in the future may cause a decrease also in investments. It will be in subject for the decrease in demand for capital in the following period to carry the fossil fuel extraction to today by decreasing the future 
interest rate compared to the present one, and thus making the green paradox effect large (van der Meijden, van der Ploeg, Withagen, 2015).

On the other hand, in case the carbon tax rate to be applied in the following period is increased more than the interest rate increase, the green paradox is likely to arise. For this reason it is important to determine the carbon tax as sufficiently high in the beginning. In the following period, if the tax is increased lower than the interest rate increase or at most equal to that, fossil fuel producers will not carry future fossil fuel production to today due to the carbon tax. In other words, when the carbon tax is determined as sufficiently high in the initial period, it will not be required to increase that tax at a rate higher than the increase in the interest rate (Edenhofer, Kalkuhl, 2011). Therefore, in the studies performed for grabbing the total effect of carbon leakage with the green paradox on global emissions, it is important whether the interest rate is being included in the established model or not. For instance, in the study performed by T. Eichner and R. Pethig (2011), it is remarkable that they had deemed the interest rate as zero.

An increase in carbon emissions would be able to occur in the transition period as from the date of announcement of a tax on carbon emissions until to the date of carbon tax implementation. This increase will occur due to the changing decisions of households regarding to savings and consumption. The households, predicting that the carbon tax making the fossil energy inputs more expensive will have an effect in decreasing the production and consumption of fossil fuels and thus will decrease the present consumption and save more in order to meet their future consumption in order to be able to mitigate the effects of the tax. This increase in savings will imply more rapid capital accumulation. As more capital will require the higher rate of fossil fuel usage, an increase will then occur in the present carbon emissions. (Smulders, Tsur, Zemel, 2012)

One of the significant factors, regarding to the effect mutually created by the green paradox and carbon leakage on global carbon emissions, is whether all the fossil fuels will be extracted from underground or not. F. van der Ploeg and C. Withagen (2015) assumes that all the fossil fuels will be extracted from underground if the carbon tax is not determined at a level which would be prohibitory and that all the fossil fuels will not be extracted in the case of the increase of extraction costs due to more fossil fuel extractions. At the same time, the decreasing cost of renewable energy resources will increase the amount of fossil fuels remaining in the ground. As is known, carbon tax cannot be applied optimally. If the tax which was applied at a low rate in the beginning is increased expeditiously, higher carbon emissions will occur in the first period, and it will be passed to renewable energy resources earlier than expected. This will imply the acceleration of global warming compared to the first best result. If the carbon tax is 
increased more gradually, the transition to renewable energy resources will be occurring later. Compared to the first best solution, more fossil fuels may remain in the ground. Here, it is being assumed that coal, natural gas and oil are only being demanded as fuels. But it is important to consider fossil fuel demand for other purposes, especially like the demand for derivatives of oil. Moreover, the condition will change in case the suppliers of fossil fuel want to determine fossil fuel prices in order to preserve and strengthen their market power. It is also important to consider that fossil fuels and renewable energy resources are not complete substitutes of each other (van der Ploeg, Withagen, 2015).

On the other hand, another significant issue regarding the effects of carbon leakage with the green paradox on global emissions is whether renewable energy and fossil fuels are being used together or not at a specific period. When it is deemed that renewable energy is a complete substitute for fossil fuels, that it is being produced in an unlimited amount over constant unit costs, and that that cost is higher than the unit cost of extracting fossil fuels in the beginning, then only the consumption of fossil fuel occurs in the beginning. If the price of oil and other fossil fuels increase adequately, the supply of renewable energy will eventually be more profitable. According to this assumption, fossil fuels and renewable energy will never be able to be used together in any period. Therefore, only fossil fuels are used in the beginning, and energy obtained only from renewable resources will be used in the future. In such a circumstance, in case the carbon tax is not imposed as high as to create a prohibitive effect on the use of fossil fuels in the beginning, the equilibrium price path will not be affected when the tax rate increases as the same rate with interest rate increase. On the other hand, in case of increasing the tax rate higher than the interest rate increase, the equilibrium price path of fossil fuels will become steeper. This means more fossil fuel extraction and more carbon emissions in the beginning. Thus, less fossil fuel extraction and fewer emissions will be in subject in the following period. And that will imply the acceleration of global warming and the decrease of green welfare in the future, and thus both a weak and strong paradox will occur. However, if the carbon tax increases at a rate lower than the interest rate increase, then oil extraction and global warming will be at a slower pace (van der Ploeg, Withagen, 2015). Moreover, as I. Österle (2015) shows that not only the extraction costs of fossil fuels but also fossil fuel exploration costs matter in regard of global carbon emissions. It may be argued that the higher carbon tax rate in the beginning compared to the future tax rates with an extraction model including exploration investments make the emergence of the green paradox having a low possibility resulting in global warming mitigation. 


\subsection{Carbon leakage along with the green paradox: some lessons learned from some studies}

The results of theoretical and empirical models related to the effects of carbon leakage and the green paradox on global emissions are able to provide significant clues to the decision makers regarding to the measures that are needed to slow down global warming.

\subsubsection{Only consumption goods production by using energy and global carbon emissions}

T. Eichner and R. Pethig (2011), by developing a general equilibrium model relevant to carbon leakage with the green paradox, presented an extensive study examining the effects of carbon reducing measures taken unilaterally by some countries on global carbon emissions. In the study, "A" (abating) and "N" (non-abating) stand respectively for countries taking and not taking measures for decreasing carbon emissions. At the same time, $\mathrm{A}$ and $\mathrm{N}$ are symmetrical countries, and they produce an " $\mathrm{X}$ " consumption product by importing fossil fuel. In the model, "F" countries are only producing fossil fuel, and they purchase product " $\mathrm{X}$ " from the A and $\mathrm{N}$ countries by the revenue obtained through exporting fossil fuel. It is assumed that the perfect competition conditions are valid in the foreign trade of " $\mathrm{X}$ " products and fossil fuels. Another assumption is that carbon emission permits are used to reduce carbon emissions. As capital investment has not been included in the model, the market interest rate is zero. For this reason, according to the Hotelling rule, the producers of fossil fuels are indifferent to selling products produced in the $1^{\text {st }}$ period (near future) or in the $2^{\text {nd }}$ period (distant future).

According to the study of T. Eichner and R. Pethig (2011), under perfect future market conditions, the size of substitution elasticity of demand in between periods determines whether the carbon leakage rate will exceed $100 \%$ or not. If country A takes emission reducing measures in the first period, the consumption product will be more expensive in the first period than in the second period. The consumers react against this by postponing the consumption in the first period to the second period. If the consumption of $\mathrm{X}$ in the first and second period are close substitute products, that is, if the substitution elasticity of demand is high, a small price increase in the first period will imply a significant increase in demand moving to the second period, and thus carbon leakage will be low. The reason for this is that the moving of a large part of the consumption of a product, whose production requires energy, to the second period is carried out. If the substitution elasticity of demand in between the periods is low or zero, in other words if the products in both periods are complementary, consumers will not be willing to postpone their consumptions to the second period despite the change in relative prices. Thus, the carbon emission in the first period will be high. 
On the other hand, according to the study of T. Eichner and R. Pethig (2011), when country A takes an emission reducing measure in the first period, this has an effect also on energy markets. According to Hotelling's rule, as fossil fuel producers are indifferent to selling fossil fuels in the first period or in the second one, its price will decrease in both periods. The decrease in energy price will increase the energy demand of country $\mathrm{N}$ in the first period. The extent of expansion of energy demand in the first period depends on the decrease in the relative price of the consumption product on one side, and on the other side, on the sensitivity of the demand of producers due to the price elasticity of demand for fossil fuels in country N. If the substitution elasticity of demand is low, consumers will continue to consume product $\mathrm{X}$ in the first period, despite the increase of relative price in the first period. The rise in this price, and fall in energy price will increase the production up to the equalization of the supply and demand of product $\mathrm{X}$ at a high level in the first period in $\mathrm{N}$. In the first period, more price elasticity of demand for fossil fuels in country $\mathrm{N}$ means more rises in energy demand and thus the possibility of the green paradox will increase. When country A follows the first period's emission reducing policy in the second period, the aforementioned result will not change. On the contrary, if country A declares in the first period that it will tighten the emission reducing measures as from the beginning of the second period, the price of product $\mathrm{X}$ in the second period will increase. In such a case, the necessary and sufficient condition for the occurrence of the green paradox is being the decrease of demand for fossil fuels. If only if the price of fossil fuels increase, the leakage rate remains below $100 \%$. In sufficiently low inter-temporal substitution elasticity values, there is not any green paradox possibility. But, according to the study, all the determinants of carbon leakage create effects in opposite directions to each other in the first and second period. Within this frame, it is not being concluded that tighter emission reducing measures in the second period would definitely cause the green paradox.

\subsubsection{How does the extraction cost of fossil fuels matter?}

One of the studies relevant to the effect of carbon leakage with the green paradox on global carbon emissions was performed by H. Ritter and M. Schopf (2014) who had actually used the model build by T. Eichner and R. Pethig (2011). But H. Ritter and M. Schopf (2014) had included the "marginal physical cost of extracting fossil fuels" in T. Eichner and R. Pethig's model. Although in the study of T. Eichner and R. Pethig (2011), the green paradox had not been distinguished as a weak and strong paradox, H. Ritter and M. Schopf(2014) used this distinction following R. Gerlagh (2011). In this new model, it had been considered that the marginal physical cost of extracting fossil fuels has a negative relationship with the remaining fossil fuels 
in the ground. By the inclusion of increasing marginal extraction costs, cumulative fossil fuel extraction is determined endogenously in the model. According to the study of H. Ritter and M. Schopf (2014), when the emission reducing measures are tightened in the second period, the price elasticity of supply in that period also plays a significant role as well as user costs in terms of conditions in which a weak green paradox will occur. And the subject of whether the strong green paradox will occur or not depends on the price elasticity of supply and the given relative weight relevant to the changes in cumulative emissions. In the first period, if the price elasticity of demand for fossil fuel and inter-temporal price elasticity of supply for fossil fuel are relatively high, and if the given relative weight relevant to the changes in cumulative emission is relatively low, the occurrence of the strong green paradox is linked to the level of inter-temporal substitution elasticity coming from more carbon reducing measures in the first period compared to the second one. If this inter-temporal substitution elasticity is lower than a specific threshold level, the strong green paradox will occur. It should be said that the occurrence of the strong green paradox is remarkable due to the increasing net present value of the costs of total carbon emissions and cumulative climate change.

Another study, with remarkable results regarding both types of green paradoxes along with carbon leakage was done by C. Fischer and S.W. Salant (2017). In this study, it is assumed that the carbon emission price is increasing at a rate equal to the increase in interest rate through such as carbon tax. In addition, it is deemed that the oil producers are price takers and the interest rate is given exogenously. According to the study, the world had been divided into two regions based on whether carbon emission reduction measures are taken or not. C. Fischer and S.W. Salant (2017) deem that the extraction cost of fossil fuels depends on the oil reserves in the ground and thus the extraction costs of oil are increasing stepwise. It is also assumed that carbon-free energy technologies are more costly than all the fossil fuel resources in the beginning. In time, the cost of carbon-free technologies will decrease and finally will be below the lowest cost of fossil fuel.

In the study of C. Fischer and S.W. Salant (2017), the effects of three different policies were analyzed by using a dynamic partial equilibrium model based on the possibility of leaving the fossil fuels in the ground in order to keep the average temperature increase of the world below 2 degrees centigrade such as in line with the Paris Agreement of 2015. According to the model, increasing the carbon tax or tightening measures for emission reduction in a carbon reducing region constitutes the first exogenous alternative. And the second alternative is to expand the carbon reducing region through negotiations. Finally, the third exogenous policy is the acceleration of technological changes for cost reduction in the field of clean energy resources. According to C. Fischer and S.W. Salant (2017), a global carbon reduction policy is 
the lowest-cost solution for the problem but the policy for decreasing the cost of clean energy by accelerating the technology has various benefits. First, the accelerated cost reduction in clean energy is directing consumers in both regions to decrease carbon emissions. Secondly, it reduces the required size of the carbon reducing region for decreasing the effect on the cumulative emissions. Thus, it allows other policies against climate change to be eased by creating cost effectiveness. In other words, even if there is a concern that rapid technological developments would cause the green paradox, the expectation is that this policy will ensure a higher increase of welfare by preventing higher carbon pricing.

\subsubsection{Carbon tax incidence on fuel exporting countries and global carbon emissions}

The study performed by F. van der Ploeg (2016) in relation to both types of green paradoxes along with carbon leakage is important because of the partly assumed backward tax shifting. In this general equilibrium model, including the world interest rate, there are three countries as K (Kyoto), N (non-Kyoto) and oil exporting country. K and N are oil importing countries According to this general equilibrium model, the carbon tax imposed by country $\mathrm{K}$ in the current period is partially shifted backwards to the oil exporting country. For the decrease in the producer price of fossil fuel to be high, and the increase in the consumer price of fossil fuel to be low, the demand for fossil fuel in country $\mathrm{K}$ is required to be higher compared to the demand in country N. In such a case, the decrease in the current demand for fuels and carbon emissions in country $\mathrm{K}$ will be relatively low. However, the increase in current demand for fuels and carbon emissions in country $\mathrm{N}$ will be relatively high. According to Hotelling's rule, a relatively high increase will occur in future demand for fuels and emissions in both $\mathrm{K}$ and $\mathrm{N}$ meaning that a large and positive carbon leakage both today and in the future will happen.

When country $\mathrm{K}$ causes more carbon emissions compared to country $\mathrm{N}$ by using more fossil fuels, the unilateral carbon tax imposed in the future by country $\mathrm{K}$ is partially shifted to the oil exporter country too. The fall in the world interest rate reduces the effect of a weak green paradox in the general equilibrium conditions. Thus, in country $\mathrm{K}$, the consumer price of fossil fuel is decreasing today and increasing in the future. On the contrary, the producer price of fossil fuel is increasing both today and tomorrow. Even though the weak green paradox effect coming from the rise in current carbon emissions in country $\mathrm{K}$ is decreasing due to the fall in the world interest rate, inter-temporal and simultaneous carbon leakages strengthen the opposite effects. This is because of the fact that the fuel demand and carbon emissions in country $\mathrm{N}$ increase both today and tomorrow. The increase in current carbon emissions in country $\mathrm{K}$, and the increase in current and future carbon emissions in country $\mathrm{N}$ are still 
unable to be completely compensated by the fall in future carbon emissions in country K. This is because there is a decrease in the producer price of oil thus creating a reducing effect on oil explorations and extractions. Therefore, despite the short term increase in current carbon emissions in countries $\mathrm{K}$ and $\mathrm{N}$, and the increase in future carbon emissions in country $\mathrm{N}$, the cumulative carbon emissions are supposed to decrease. But the rent grabbing effect of carbon tax imposed in the future by country K negatively affects the welfare of both countries $\mathrm{N}$, and the oil exporting country. In other words, the unilateral welfare of country $\mathrm{K}$ is able to increase despite the strong green paradox effect. The effect of inter-temporal terms of trade on unilateral welfare is proportional to the future trade balance of country $\mathrm{K}$.

\section{Conclusions}

The global carbon emission reducing effect of a climate policy instrument such as carbon tax is relevant to its effect on fossil fuel prices, and thus on fossil fuel demand and supply. As is known, carbon tax is actually an instrument intending to reduce carbon dioxide emissions by increasing the price of fossil fuels and decreasing the demand for them. But it is argued that various factors determining the effect of carbon leakage with the green paradox on global carbon emissions are important. Under the assumption that the interest rate and fossil fuel extraction costs remain the same, when measures for reducing carbon dioxide emissions are taken by some countries, the inter-temporal substitution elasticity of the demand for consumption products produced by using energy from fossil fuels determines whether the leakage rate will exceed $100 \%$ or not, Secondly, the price elasticity of demand for fossil fuels in different periods is also important. Naturally, the present and future changes of fossil energy prices are relevant to the size of the inter-temporal substitution elasticity of demand for consumption products produced by using fossil energy. When it is deemed that fossil fuel extraction costs are gradually increasing, the price elasticity of supply is also another factor that determines global carbon emissions.

It is important to consider the effects of carbon leakage in the case when carbon emission reducing measures taken by some countries or all countries on interest rates as the discount rate thus causing the green paradox effect. In this respect, as the inclusion in the interest rate as a variable in the models is important in terms of obtaining the loadstar results for decision makers, the issues linked to how fossil fuel prices are being determined, and whether the carbon tax implemented by only developed countries can be shifted forward or not are also valuable. On the other hand, the inclusion the interest rate as a variable in the models is a significant step, 
we can argue that it is also vital to consider the factors that affect interest rates. For instance, it is important to take into account that the fall of real interest rates by the saving surplus arising from the decrease in investments due to a global crisis may cause the postponement of the extraction of fossil fuels.

If the tax rate is increased at a higher rate than the interest rate, the equilibrium price path of fossil fuels will become steeper. This will imply both weak and strong green paradoxes will occur thus leading to the acceleration of global warming and a reduction of green welfare in the future. But in the addressed studies, the effect of carbon leakage with the green paradox on global carbon emissions is analyzed by assuming that the carbon tax or carbon dioxide emission price is increased at a rate equal to or lower than the interest rate. This condition already indicates the limit that only the green paradox will not occur. By assuming this limit, it is not possible to get realistic results by analyzing the possibility of a weak or strong green paradox with carbon leakage. Moreover, the issues such as what the initial level of carbon tax is and the fossil fuel extraction from the known reserves will not be able to be promptly increased without making an investment should be considered in terms of global emissions.

On the other hand, another significant issue in relation to the mutual effects of carbon leakage and the green paradox on global emissions is whether renewable energy and fossil fuels are being used together or not at a specific period. It is possible to obtain more realistic results by including the assumption that energy from fossil fuels is used together with renewable energy from the sun and wind especially in the beginning in the general equilibrium models. Moreover, we should say that, it is essential to take into account that the fossil fuel producing and exporting countries will be in need of more foreign currency today and tomorrow. This will be because the large fossil fuel producing countries in the world may need less income from fossil fuels in the following period due to more tax revenue collected after the tax reforms made in the present time. At the same time, that some large fossil fuel producing countries want to determine the fossil fuel prices in order to preserve and/or strengthen their market powers has an important effect on fossil fuel prices today and tomorrow. For the market power of especially oil producing countries, one should take into account the fact that fossil fuels like oil are not used only for energy production, but also used as an input for production derivatives like plastic and tires.

The effect of carbon leakage with the green paradox on global carbon emissions also depends on the discovery of new fossil fuel reserves in the future. Because the reserves to be discovered in the future will determine global carbon emissions depending on the inter-temporal substitution elasticity of demand for products produced by the energy from fossil fuels, and the price elasticity of demand and supply for fossil fuels, we can argue that the inclusion of fossil 
fuel reserves to be discovered in the future into the models is important in terms of revealing realistic effects. Naturally, it is important to underline the fact that the reserves discovered in the future will be extracted depending on the fossil fuel prices in that period, forecasts linked to the prices in the period after discovery, and the interest rates.

Finally, we can argue that it is important to consider the discovery of new fossil fuel reserves in the future linked to fossil fuel producing and exporting countries in need of more foreign currency today and tomorrow and the factors affecting the interest rates in order to see the mutual effect of carbon leakage and the green paradox on global carbon emissions. Therefore, future studies taking into consideration fossil fuel reserves to be discovered in the future and factors like the global economic crisis or global health problems such as Covid-19 changing the interest rates in their general equilibrium models will contribute to more effective policies against global warming.

\section{References}

Arce, M.D.G. (2004). Asymmetric Leadership and International Public Goods. Public Finance Review, 32, 528-558. DOI: 10.1177/1091142104265876.

Barrett, S. (1999). Montreal versus Kyoto: International Cooperation and Global Environment. In: I. Kaul, I. Grunberg, M.A. Stern (eds.), Global Public Goods, International Cooperation in the 21st Century (pp. 192-219). New York, NY: Oxford University Press.

Cairns, R.D. (2014). The Green Paradox of the Economics of Exhaustible Resources. Energy Policy, 65, 78-85. DOI: 10.1016/j.enpol.2013.10.047.

Cline, W.R. (1991). Scientific Basis for the Greenhouse Effect. The Economic Journal, 101 (407), 904-919. DOI: 10.2307/2233863.

Coulomb, R., Henriet, F. (2018). The Grey Paradox:How fossil-fuel owners can benefit from carbon taxation. Journal of Environmental Economics and Management, 87, 206-223. DOI: $10.1016 /$ j.jeem.2017.07.001.

Criqui, P., Jaccard, M., Sterner, T. (2019). Carbon Taxation: A Tale of Three Countries. Sustainability, 11 (2), 1-21. DOI: 10.3390/su11226280.

Dinan, T.M. (2009). Reducing Greenhouse Gas Emissions with a Tax or a Cap: Implications for Efficiency and Cost Effectiveness. National Tax Journal, 62 (3), 535-553.

Droege, S. (2011). Using Border Measures to Address Carbon Flows. Climate Policy, 11, 11911201. DOI: 10.1080/14693062.2011.592671. 
Eckersley, R. (2010). The Politics of Carbon Leakage and the Fairness of Border Measures. Ethics and International Affairs, 24 (4), 367-393. DOI: 10.1111/j.1747-7093.2010.00277.x.

Edenhofer, O., Kalkuhl, M. (2011). When Do Increasing Carbon Taxes Accelerate Global Warming? A Note on the Green Paradox. Energy Policy, 39, 2208-2212. DOI: 10.1016/j. enpol.2011.01.020.

Eichner, T., Pethig, R. (2011). Carbon Leakage, The Green Paradox, and Perfect Future Markets. International Economic Review, 52 (3), 767-805.

Fischer, C., Salant, S.W. (2017). Balancing the Carbon Budget for Oil. European Economic Review, 99, 191-215. DOI: 10.1016/j.euroecorev.2017.04.003.

Fölster, S., Nyström, S. (2010). Climate Policy to Defeat the Green Paradox. Ambio, 39, 223235. DOI: $10.1007 / \mathrm{s} 13280-010-0030-7$.

Gerlagh, R. (2011). Too Much Oil. CESifo Economic Studies, 57 (1), 79-102. DOI: 10.1093/ cesifo/ifq004.

Herber, B.P., Raga, J.T. (1995). An International Carbon Tax to Combat Global Warming: An Economic and Political Analysis of the European Union Proposal. American Journal of Economics \& Sociology, 54 (3), 257-268. DOI: 10.1111/j.1536-7150.1995.tb03422.x.

Hoel, M. (2011). The Supply Side of CO2 with Country Heterogeneity. Scandinavian Journal of Economics, 113 (4), 846-865.

Kuik, O., Gerlagh, R. (2003). Trade Liberalization and Carbon Leakage. The Energy Journal, 24 (3), 97-120.

Österle, I. (2015). The Green Paradox and the importance of endogenous resource exploration. Australian Journal of Agricultural and Resource Economics, 60, 60-78. DOI: 0.1111/1467-8489.12103.

Ritter, H., Schopf, M. (2014). Unilateral Climate Policy: Harmful or Even Disastrous? Environmental Resource Economics, 58, 155-178.

Sandler, T. (2003). Assessing the Optimal Provision of Public Goods: in Search of the Holy Grail. In: I. Kaul, P. Conceiçao, K. Le G. Goulven, R.U. Mendoza (eds.), Providing Global Public Goods, in Managing Globalization (pp. 131-151). New York, NY: Oxford University Press.

Sinn, H.W. (2008). Public Policies Against Global Warming: A Supply Side Approach. International Tax and Public Finance, 15 (4), 360-394. DOI: 10.1007/s10797-008-9082-z.

Smith, J.L. (2012). Issues in Extractive Resource Taxation: A Review of Research Methods and Models. IMF Working Papers, 12/287.

Smulders, S., Tsur, Y., Zemel, A. (2012). Announcing Climate Policy: Can a Green Paradox Arise Without Scarcity? Journal of Environmental Economics and Management, 64, 364376. 
van der Meijden, G., van der Ploeg, F., Withagen, C. (2015). International Capital Markets, Oil Producers and the Green Paradox. European Economic Review, 76, 275-297.

van der Ploeg, F., Withagen, C. (2015). Global Warming and the Green Paradox: A Review of Adverse Effects of Climate Policies. Review of Environmental Economics and Policy, 9 (2), 285-303. DOI: 10.1093/reep/rev008.

van der Ploeg, F. (2016). Second-best carbon taxation in the global economy: The Green Paradox and carbon leakage revisited. Journal of Environmental Economics and Management, 78, 85-105. DOI: 10.1016/j.jeem.2016.02.006. 